\title{
Living donor satisfaction survey in Myanmar
}

\author{
Yee Yee Myint, Khin Thida Thwin
}

Department of Nephrology, Yangon Specialty Hospital, Yangon, Myanmar

Background: Living donation is a strategy to tackle organ shortage for transplantation, but it requires protection of the donor. The aim of this study was to evaluate living donor's satisfaction and dissatisfaction with their donation process.

Methods: This survey was conducted as a prospective descriptive and cross-sectional study from July to December 2020 at Yangon Specialty Hospital by using "Questionnaire of the European Living Donation and Public Health-Satisfaction Survey".

Results: Fifty living kidney and liver donors were interviewed. Of the 50 participant, $58 \%$ were female and $42 \%$ were male. Years of donation was 2014 to 2020, $(n=32,64 \%)$ was $1-5$ year $(n=11,22 \%)>5$ year and $(n=7,14 \%)$ within 1-year duration. Donor-recipient relationship was: siblings $(n=22,44 \%)$, relatives $(n=14,28 \%)$, offspring $(n=8,16 \%)$, parents $(n=5,10 \%)$, and non-related $(n=1$, $2 \%)$.Organs donated were mainly kidney $(n=38,76 \%)$, and liver $(n=12,24 \%)$. Regarding informed consent, >90\% respondents were satisfied with the information given before donation. Medical attention they received during and after donation was sufficient for almost all donors (94\%). Eighteen donors (36\%) considered the medical test more bothersome than expected. Forty donors (80\%) were suffered pain and discomfort after donation. Being a donor, there was some impact on economic loss ( $\mathrm{n}=7,14 \%$ ), their job $(n=9,18 \%)$ in a negative way. Five donors (10\%) felt pressured to be a living donor. Eighteen donors (36\%) would not go again through all these procedures. But there is no one who regretted the donation after surgery.

Conclusions: There was slight gender disparity due to female are more dependent and male are a bread winner. Majority of donors accept donation process willingly. But small percentage did not meet their expectancies. This need to be addressed the discrepancies between donor's expectation and actual experiences. By doing so, we can improve Organ Donation Program in an effective way.

Corresponding author: Khin Thida Thwin

E-mail: drkhinthidathwin@gmail.com

(C) The Korean Society for Transplantation

This is an Open Access article distributed under the terms of the Creative Commons Attribution Non-Commercial License (http://creativecommons.org/licenses/by-nc/4.0/) which permits unrestricted non-commercial use, distribution, and reproduction in any medium, provided the original work is properly cited. 